\title{
The Use of Measurement Uncertainty on Clinical Laboratories Results
}

\author{
Kübranur Ünal* \\ Department of Biochemistry, Ankara Polatlı Public Hospital, Ankara, Turkey
}

Received: December 21, 2017; Published: January 05, 2018

*Corresponding author: Kübranur Ünal, Ankara Polath Public Hospital, Karapmar Mahallesi, Eskisehir yoluüzeri Abdülaziz Cad. No: 2, 06900, Ankara, Turkey, Tel: 0903126303030-1102; Email: dr.kubranur_unal@outlook.com

\section{Opinion}

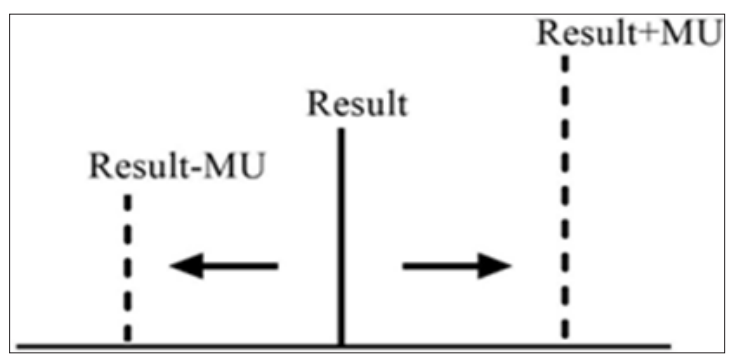

Figure 1: According to ISO 15189, MU should be provide available by the laboratory on request.

Clinical laboratories should produce the required data and analytical results in order to achieve the true interpretation and use of the results. The objective of a measurement is to detect an estimate for the true value of analytical results. The measurement uncertainty (MU) is a parameter, associated with the result of a measurement that characterizes the distribution of the values that could reasonably be attributed to the measure and [1]. Clinicians might interpret better at clinical decision levels knowing the MU of a test. The interpretation of values which are close to cut-off levels may change, when they evaluated with MU. Therefore, reporting clinical laboratories results with estimation of MU is significant to show measurements that contained within the true limits and the level of confidence. With the acceptance of the International Organization for Standardization (ISO) laboratory standard Medical Laboratories - Particular Requirements for Quality and Competence (ISO 15189), laboratories have been required to provide estimates of MU for all quantitative test results [2]. According to ISO 15189, MU should be provide available by the laboratory on request (Figure 1).
MU provides quantitative estimates of the level of confidence that a laboratory has in its analytical precision of test results and therefore represents the expected variability in a laboratory result if the test is repeated a second time [3]. MU consists measuring procedure components which are pre- and postan alytical variation and biological variation [4]. Limit values of laboratories results (within MU) are being more careful follow-up and alarming the clinician. MU is the appropriate approach for meaningfully comparing measurement results with reference values. In our opinion, the clinicians must take into account of the MU during the evaluation of clinical laboratories results. We trust that MU can help clinicians and patients to better understand the accuracy of results and evaluate clinical decision levels. At the same time, MU is useful for clinical decision but have yet to show their strength in laboratory medicine. Also, the MU is still new in the field of quantity measurement. The pros and cons of uncertainty should elucidate on their use in practical performance specifications.

\section{References}

1. Guide EC (2000) Quantifying uncertainty in analytical measurement. Laboratory of the Government Chemist, London.

2. Yanikkaya-Demirel G (2009) ISO 15189 accreditation: Requirements for quality and competence of medical laboratories, experience of a laboratory II. Clinical biochemistry 42(4): 279-283.

3. Magnusson B (2003) Handbook for calculation of measurement uncertainty in environmental laboratories.

4. Oosterhuis WP, Bayat H, Armbruster D, Coskun A, Freeman KP, et al. (2017) The use of error and uncertainty methods in the medical laboratory. Clinical Chemistry and Laboratory Medicine (CCLM). 


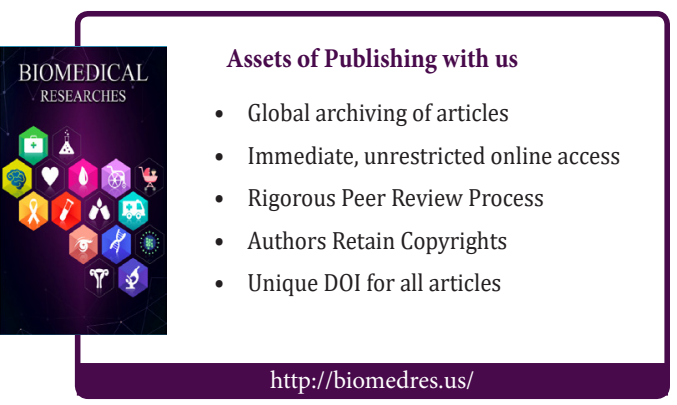

